\title{
DOCUMENTATION AND DISSEMINATION OF THE SCULPTURAL ELEMENTS OF CANADA'S PARLIAMENTARY BUILDINGS: METHODOLOGY DEVELOPMENT AND EVOLUTION, A CASE STUDY
}

\author{
C. Ouimet $^{\mathrm{a}}$, J. Gregg ${ }^{\mathrm{a}}, \mathrm{S} . \mathrm{Kretz}^{\mathrm{a}}$, C. Chandler ${ }^{\mathrm{a}}{ }^{\mathrm{J} . \text { Hayes }}{ }^{\mathrm{b}}$ \\ ${ }^{\text {a }}$ Heritage Conservation Directorate, Public Works and Government Services Canada, 30 Victoria St, Gatineau, Quebec, Canada - \\ (christian.ouimet, john.gregg, shawn.kretz, caise.chandler)@pwgsc.gc.ca \\ ${ }^{\mathrm{b}}$ Carleton Immersive Media Studio, Carleton University, 1125 Colonel By Dr, Ottawa, Ontario, Canada - jhayes@cims.carleton.ca
}

Commission VI, WG VI/4

KEY WORDS: Photogrammetry, Photography, Dissemination, Close Range Scanning, Masonry, Sculptural Elements, CNC, 3D Printing.

\begin{abstract}
:
Parliament Hill consists of four historic gothic revival buildings, which form part of the Parliament Buildings National Historic Site of Canada in the National Capital of Ottawa. There are more than 2000 masonry sculptural elements throughout the four buildings. Three of the buildings are in the middle of multi-year rehabilitation projects. Extensive Heritage Documentation is being undertaken to support various activities and conservation teams throughout the interior and exterior of the buildings while also serving as a key posterity records. One of the significant heritage documentation projects is the 3D digitization of the 2000+ heritage character defining sculptural elements. The Heritage Conservation Directorate (HCD) of Public Works and Government Services Canada (PWGSC) was tasked by the Parliamentary Precinct Branch (PPB) of PWGSC to document these character defining elements. The sculptures vary in size from as small as $100 \mathrm{~mm}$ in width to up to 2 meters in size. This project is in its third year and much has been learned and researched about the most appropriate and efficient means by which to document these elements. Although a methodology was in place to document the sculptures at the inception of the project, it has gone through several iterations in order to improve the gathered data, and in turn increase the efficiency, quality and speed of data acquisition. This paper will describe the evolution of the methodology, as well as the rationale for the alterations in technique.
\end{abstract}

With over 600 of the approximate 2000 (heritage character defining) sculptural elements captured to date, the project is entering a critical phase where an efficient and effective method for sharing and disseminating the information to a wide audience is being explored and evaluated. The end result is intended to allow the client (PPB) and the general public a way to look at and interactively manipulate the viewpoint of each digital model. This will provide a unique opportunity for a wide audience to evaluate and appreciate these elaborate works of art. This database of information can also be of use for academic study and research.

To date the data captured by HCD has been utilized by conservation professionals and by the Carleton Immersive Media Studio (CIMS) of Carleton University. HCD has partnered with CIMS to explore a wide variety of potential uses for the data including the creation of 2D-drawings, stone carving profile templates, 3D printed scale models, CNC carved maquettes, robotic stone carving, and digitally-designed replacement elements. CIMS and HCD have tested the limits of digital technologies to assist stone carvers in restoring carved elements while also learning from the sculptors and masons to better understand their approach when conserving or restoring a sculptural element. Examples of how the conservation team, specifically the stone carvers have been working with the data and technology will also be presented.

\section{INTRODUCTION}

The Parliament Buildings of Canada sit on Parliament Hill in Ottawa, Ontario on an escarpment that overlooks the Ottawa River. The hill is located in the downtown core of the city immediately west of the northern limit of the Rideau Canal, a UNESCO World Heritage Site. The buildings, which form part of the Parliament Buildings National Historic Site of Canada, were constructed from 1859 to 1868 and are called: East Block, Centre Block, the Library of Parliament, and West Block. The four buildings are designed in the stylistic character of Gothic Revival and they are designated as Classified Federal Heritage Buildings forming some of the best mid- $19^{\text {th }}$ century Gothic Revival buildings in the world. Staying true to the nature of the building's design there are more than 2000 heritage character defining sculptural elements located throughout the exteriors and interiors of the buildings.

After more than one hundred and fifty years, space, services and systems within the buildings on Parliament Hill have become inadequate. As such, a multi-year rehabilitation project is currently underway in which the West Block is being conserved with the Centre Block and East Block scheduled to undergo similar treatments in the near future. The Library of Parliament was extensively rehabilitated between 2002 and 2006.

This project forms only a small component of many significant documentation projects that are underway and involved in the conservation process of the Parliament Buildings. This paper describes the role of the documentation and dissemination of the heritage character defining sculptural elements in the conservation of Canada's Parliament Buildings. 


\section{ACQUISITION WORKFLOW}

Time and careful consideration was given to ensure that an appropriate methodology was developed to ensure adequate and efficient capturing of the sculptural elements was possible prior to the onset of the West Block rehabilitation project. However, as the project progressed it became evident that it was necessary for the initial methodology to evolve with the project.

The original methodology was developed using a combination of a Creaform HandySCAN 3D handheld scanner and supported with digital photogrammetry using a full frame Nikon D3X DSLR camera.

The Creaform HandySCAN 3D scanner is a data acquisition system with its own positioning system. This means that no external tracking or positioning devices are required. It uses triangulation to determine its relative position to the object in real time. Two principle cameras cast light on the object being scanned while a third camera captures the colour value of the object. The system requires proprietary VXelements software installed on a notebook computer while connected to the scanner in order to capture and view the scanned object in real time. Accuracy is accomplished using reflective sticker positioning targets placed on the object in a distribution pattern of $50-75 \mathrm{~mm}$ apart from one another. By capturing the constellation of targets, the software is able to generate an accurate 3D mesh of the object. This tool was initially selected for: ease of use, versatility, speed of acquisition, automatic/direct mesh output, quick workflow integration and real time visualization ensuring complete data capture.

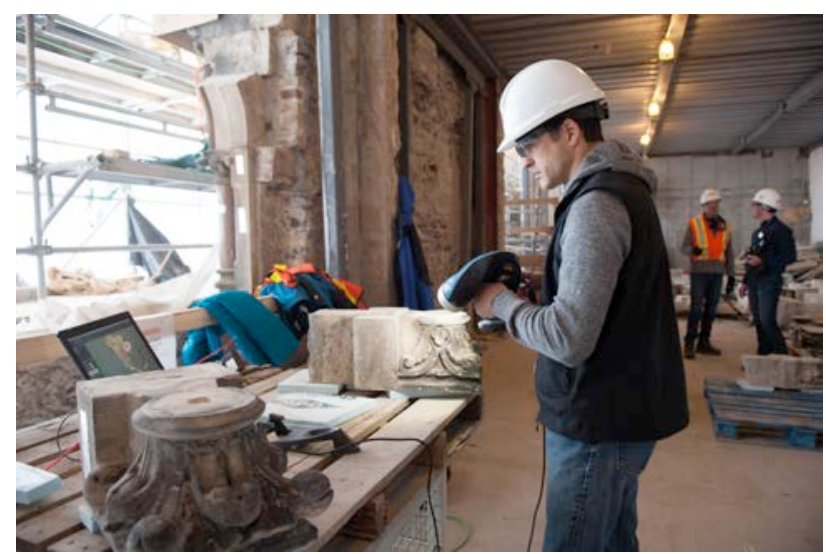

Figure 1. Data capture with a Creaform HandySCAN 3D handheld scanner.

Although the handheld scanner has the ability to capture the colour value of the surfaces being scanned, it was found that the device did not meet the quality of a digital camera. Therefore, several photographs of each element were also captured using a DSLR camera and then superimposed onto the mesh combining the two sets of data using PhotoScan, a photogrammetric software package by Agisoft. This allows users other than a specialized photogrammetrist to produce relatively accurate $3 \mathrm{D}$ models from images taken using specific photogrammetric techniques. The result is a consistent and accurate mesh with a highly detailed texture.

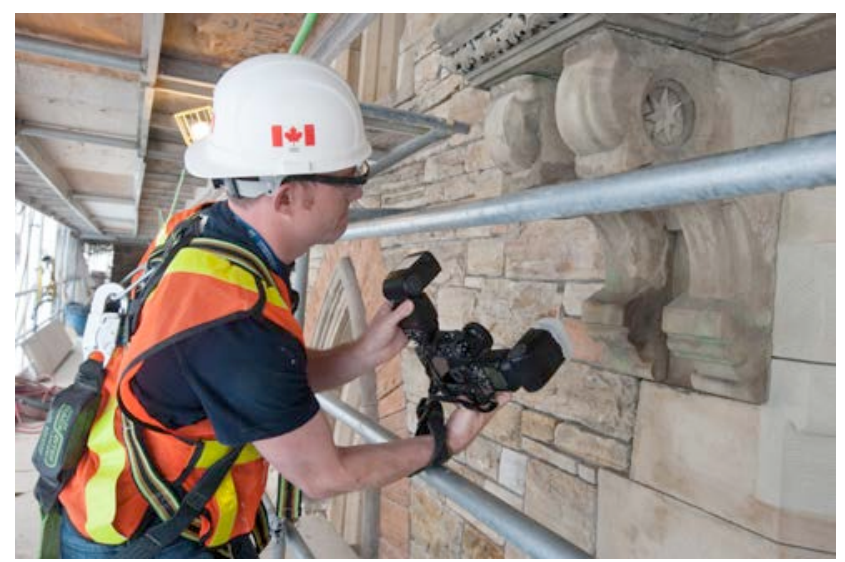

Figure 2. Data capture with a Nikon D3X DSLR camera.

The first step in of the initial methodology process involved applying the reflective sticker positioning targets to the sculpture and surrounding surfaces. The number of targets ranged from \pm 30 for small sculptures $(100 \mathrm{~mm} \times 100 \mathrm{~mm} \times$ $100 \mathrm{~mm})$ to over \pm 150 targets for large sculptures $(1.5 \mathrm{~m} \mathrm{x} 1.5 \mathrm{~m}$ $\mathrm{x} 1.5 \mathrm{~m})$. This application proved to be time consuming and costly depending on size and complexity of the sculpture.

Once the application of targets on the first sculpture was completed, the hand scanning was initiated. While scanning was in progress, a second person continued to apply targets on the subsequent sculptures, which allowed for continuous scanning between sculptures without delay. For effectiveness, this was always a two-person process.

When the scanning of the first sculpture was completed, the second person would go back and remove some of the targets, and complete the photogrammetry component of the process using the DSLR camera. A few well distributed targets were left on the element and captured with the photogrammetric images. This ensured that common coordinates were visible in both the scanned model and photogrammetric images. For this method, the first step required orientation of the scanned model to allow for a more precise orthographic orientation of the model. Models were then oriented using a flat planar surface as well as any dominant horizontal element to orient the xyz axes. After the scanned model was reoriented the xyz coordinates of the centre of three or four positioning targets were located in both the scans and photos.

This original methodology achieved a capture rate of on average six to seven sculptures per day. Initially, the team had estimated the capture of 10-15 sculptures a day would be possible.

The following is a list of the pros and cons of using the Creaform HandySCAN 3D scanner that were determined for this project.

\subsection{Pros}

- Scanning the sculptures provides consistent lighting and smooth point cloud finish. This works well in areas where lighting conditions are poor.

- The user can be confident that the data is complete because they can see the results of the scan in real time during data acquisition.

- The 3D mesh generated by the scanner is complete requiring minimal to no post-processing.

- The resulting model can be highly detailed with a maximum resolution of 200 microns and an accuracy of 100 microns. 


\subsection{Cons}

- Placement of targets on stone sculptures is time consuming; also they do not adhere well on stone sculptures that are in a dusty or wet environment.

- The cost and usage rate of the reflective sticker positioning targets.

- Occlusions are quite high on sculptures with undercuts and relief.

- Digital photography is needed if a high quality texture is required.

- When forced to use batteries for both the laptop and scanner, we found the battery option significantly slows down the data transfer rate. This can lead to slow real-time viewing and can be difficult to follow.

As a result of the low sculpture capture rate, the team reevaluated its approach for documentation in order to speed up the data acquisition. Through our gained experience on this project HCD determined that by combing methods of photogrammetry with the use of automated target system worked best and is the most efficient means of capturing the sculptural elements. This was done with the PhotoScan software package.

The PhotoScan software can create auto-detectable targets, which are printed out onto foam board with assigned xyz coordinates. Two auto-detectable targets are placed onto a ruler or similar object to create a scalebar. Both the foam board, which includes four control points, and for the larger sculptures a scalebar is adhered to the surface on the main plane close to the sculpture. This allows for easy orientation and registration of the model during post-processing. Where possible, the foam board is adhered to the surface perpendicular to the main plane and level to ensure that the final registered model is automaticaly in the proper coordinate system.

Approximately six images of the sculpture are taken with the foam board and/or scalebar present in the photos. After completing the photogrammetry of the sculpture, the foam board and/or scalebar are removed to ensure that they are not present in the final 3D model. On average, about 50 RAW images are taken per sculpture to eliminate as many oclusions as possible. With the use of two strobe lights, the majority of the shadows in the deep crevices and holes are removed and a consistent level of lighting is achieved.

The RAW image format also provides the option to postprocess the images in instances where the detail in shadows needs to be drawn out. This would be more dificult if using nonRAW image formats such as JPEG images. RAW also takes advantage of other benefits, such as exposure (RAW files have a higher dynamic range) and the ability to adjust the white balance of the images. The main disadvantage of RAW is the large file size and data storage requirements. With over a 1000 scultural elements to capture at West Block alone at \pm 50 images each, the resulting data set is extremely large. Folders and images are named using a common system developed by PWGSC, and all the data is downloaded onto the network and an external hard drive repository for posterity.
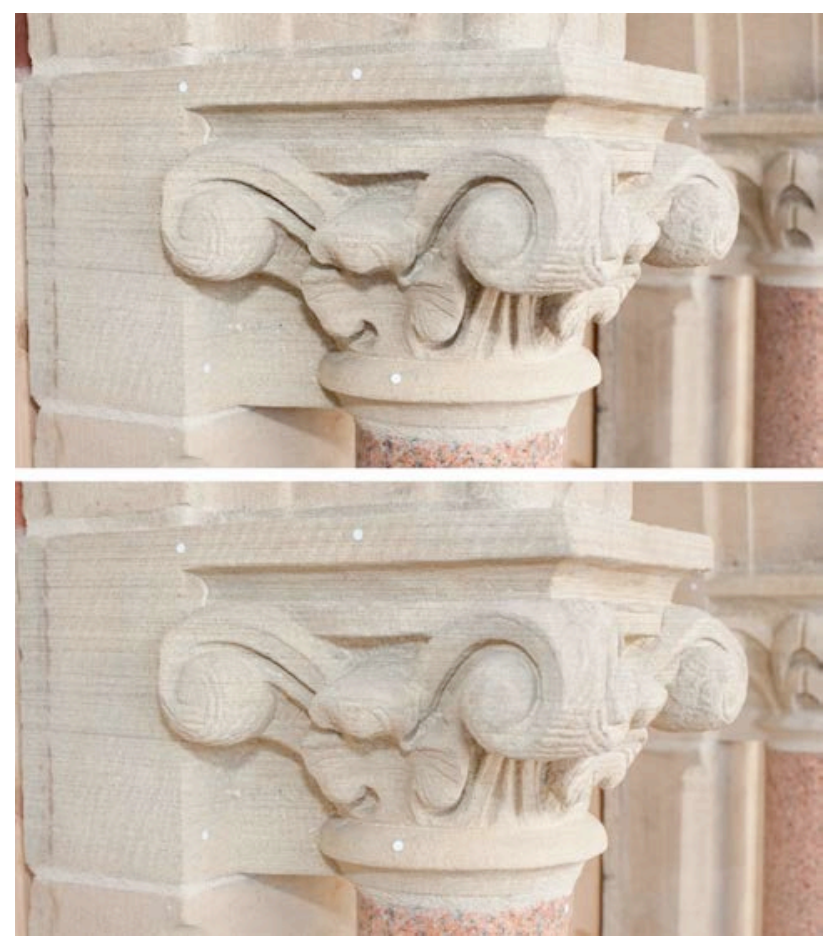

Figure 3. RAW file format images adjusted to gain detail information in shadow areas.

Using the new methodology we are able to document 13 to 14 sculptures per day, more than doubling our previous acquisition rate.

\section{PROCESSING OF CAPTURED IMAGES}

Sculptural elements found throughout Parliament Hill were inventoried, catalogued and numbered by former dominion sculptor Marcel Joanisse. Each carving was assigned its own unique number. In the case of the West Block, an interactive PDF photographic database was created for each elevation of the building. Each carving has its own entry with high resolution photographs and a detailed description of the sculpture. This database and in particular, the numbering system was essential in the development of the project and used to guide the recording of each element. Each sculpture was captured using photographs and in some cases hand scanning, named and stored according to the Joanisse system. This allows for simplified retrieval and cross-referencing ensuring no element is missed.

Prior to model creation, the workflow consists of file format conversion, from RAW to JPEG image format as well as minor exposure adjustments, ensuring the preservation of shadows and image fidelity. Sufficient contrast is required to allow the photogrammetric software to find common tie points. This is challenging at times given that flash photography was required for all of the sculptures due to low light conditions within the scaffold.

Using HCD's current methodology PhotoScan is used to process and generate the $3 \mathrm{D}$ models of each sculpture. This software package allows for the batch processing of many of the steps, greatly simplifying the model creation process and operator time. A new project file is created in the software according to its sculpture number. The images are imported into the project and are then aligned to each other automatically detecting the common tie points, which in turn generates a sparse point cloud. 
The revised method relies on independent control placed on the model. Foam boards of different sizes (Figure 4) are set on the model, parallel to the predominant plane of the sculpture. Each board has four auto-detectable PhotoScan targets with assigned xyz coordinates contained in a text file for each specific foam board. This allows for the orientation of the model as well as rudimentary scaling. Using a scale bar with the same PhotoScan targets applied at a known distance further refines the scale of the model.

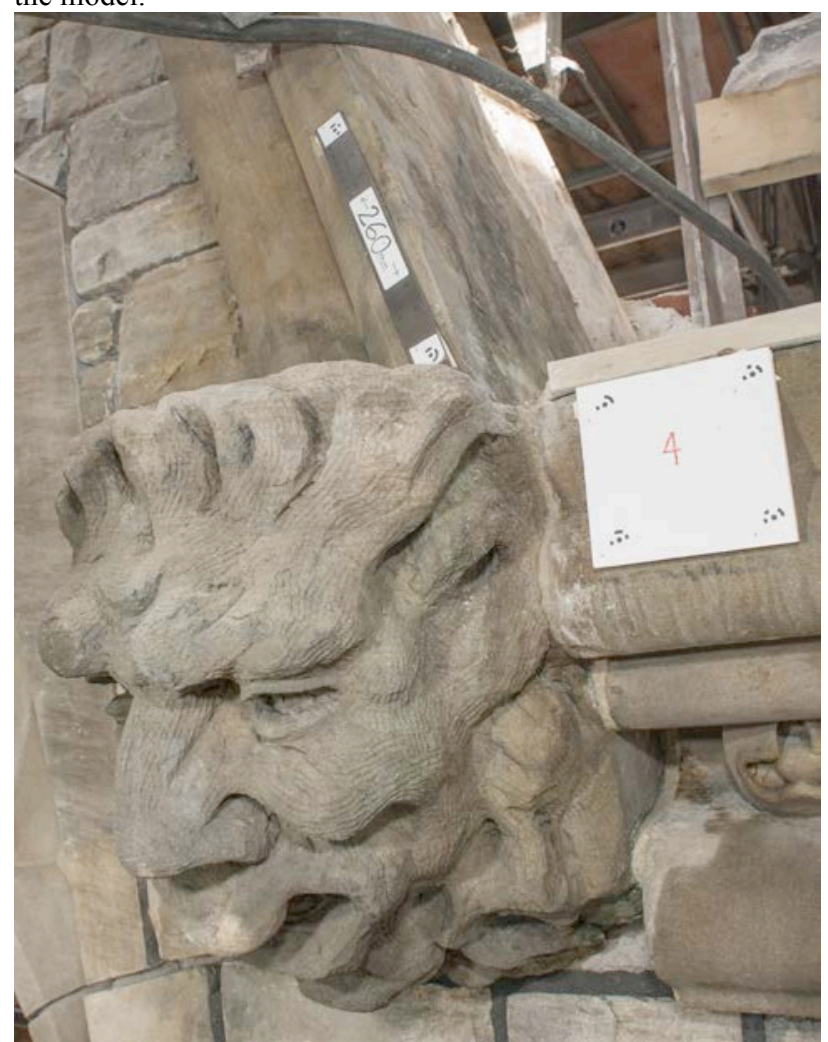

Figure 4. Photogrammetric image with known control points.

The model is then batch processed to finalize the dense point cloud, mesh and texture of the model. The resolution of the resulting model can be $0.5 \mathrm{~mm}$ or less and with an accuracy of up to $0.3 \mathrm{~mm}$ depending on the photo scale. It can then be exported in a variety of formats and resolution settings depending on the requirements of the end user.

Other photogrammetric software options are continually being explored. One software package, Smart 3D Capture by Acute $3 \mathrm{D}$, provides models with more detailed edges when compared with PhotoScan (Figure 5). However, the process to generate the models is not as streamlined as Photoscan. But in cases where more detailed specific models are required, these can be produced with this software.
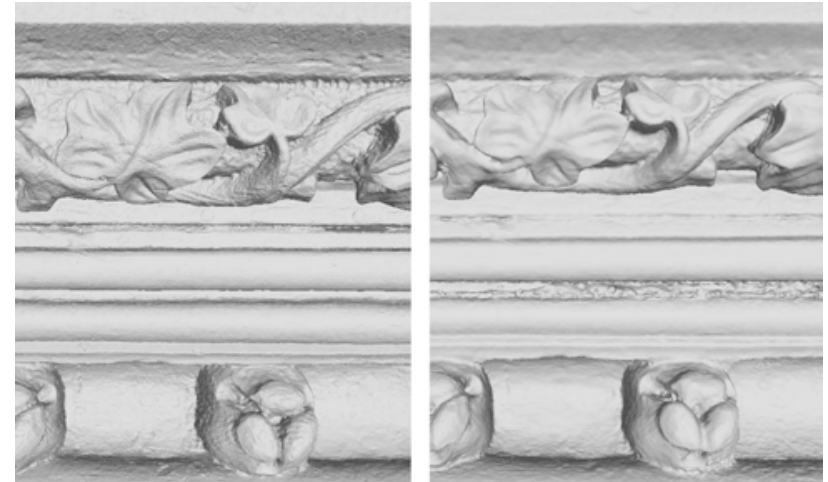

Figure 5. Model comparison - Acute 3D (left) and PhotoScan(right).

\section{DISSEMINATION}

With hundreds of models that have been captured and hundreds more to complete, resources are dedicated to exploring dissemination and archiving options. HCD's first priority is to develop a platform for PPB to allow easy access to the models. This platform could also eventually be made available to a wider audience, such as visitors to the site that do not see the intricate details of the sculptures that are not visible from the ground. This information could also possibly be made available to the public via the Internet.

There are fortunately several online tools and repositories for textured meshes. Several were studied, and most are quite similar. Models must be uploaded to a cloud server, and then optionally an interface such as an HTML page to catalogue the models was built. Existing building elevations were used to build a graphic interface that shows the locations of the elements, and allows the user to select the sculpture that they would like to view. The HTML page can be on a server or on a USB drive; but, to gain access to the models an internet connection is required. Some model hosting services are free, and also come with some privacy settings in cases where models must only be visible to specific users.

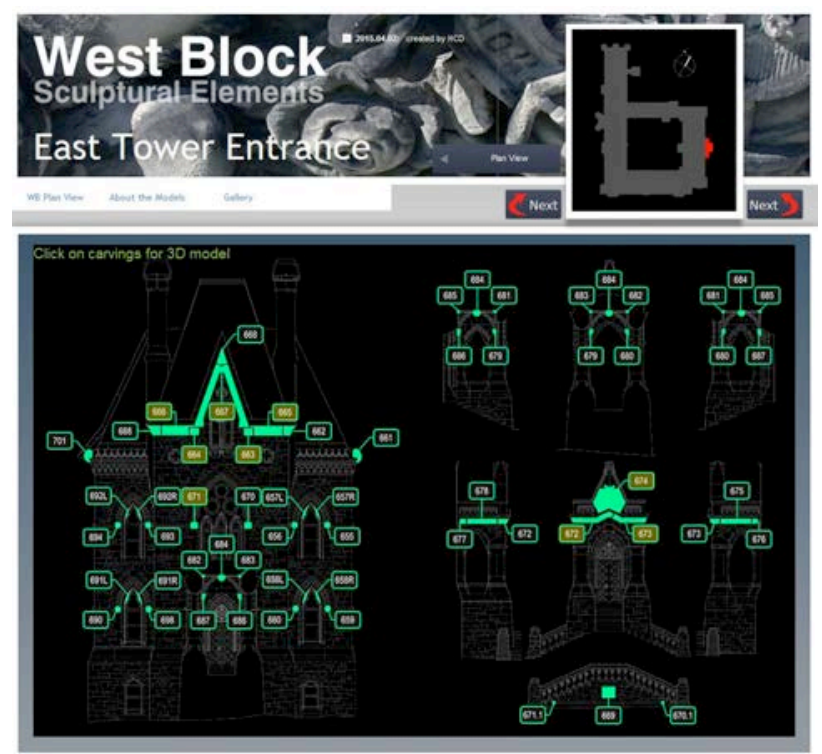

Figure 6. HTML graphic interface. 


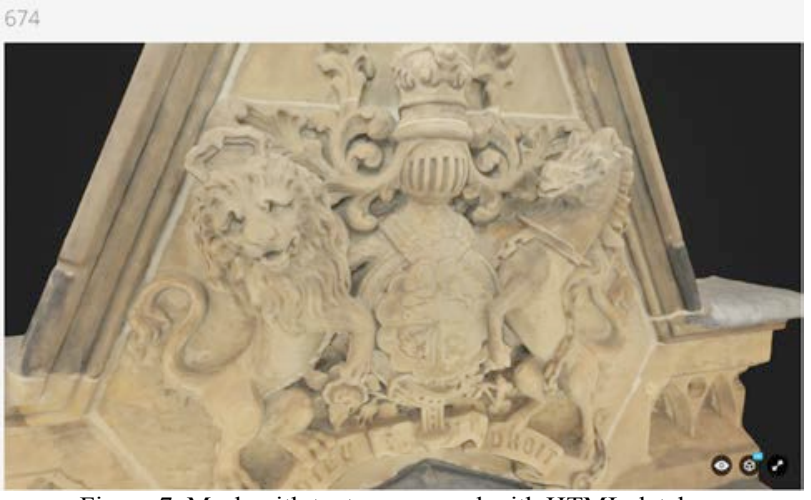

Figure 7. Mesh with texture, opened with HTML database

\section{USES OF DOCUMENTED SCULPTURAL ELEMENTS}

Although the primary motivation of the documentation was to capture the sculptural elements for posterity purposes, the team explored possible short term uses for the captured data. Possible uses were explored with the CIMS team and conservation professionals working on the rehabilitation project. One of these groups was the stone carvers. They were approached to explore ways that the captured data could be used to assist them with their work.

One of the traditional techniques which stone carvers employ in the process of replacing or repairing damaged sculptural elements is the creation of a plaster copy of the damaged element. The plaster copy is made by first creating a plaster mold of the stone sculpture. The copy serves as a base for the carvers to rebuild the damaged areas with modelling clay. The plaster and clay model is used to guide the carver in the carving of the new stone sculptural element, typically done with a pointing machine.

The data from close-range laser scanners and photogrammetry makes it possible to provide a variety of alternatives to the plaster copy. The following is a list of how this information has been used specifically in the West Block rehabilitation project.

\subsection{Window Reinstatement}

A series of windows that were significantly altered in the 1960 s are being reinstated as part of the current rehabilitation of the West Block. The masons were directed by the architect to copy sculptural elements from other areas of the building for the reinstated windows. However there was no scaffolding in place to measure, photograph, or make plaster copies of the example sculptural elements. As part of the work to scan the 2000+ elements on the West Block, the example elements that were already digitized were used.

The example elements to be copied were relief sculptures of regular geometry and therefore two-dimensional information was sufficient information to allow masons to carve the new elements. From the scan data, HCD provided two-dimensional sections and elevations at full scale. The elevations provided the overall shape of the elements, while the sections provided depth and the extent of any undercuts present.

\subsection{Arms of Canada Repair: Robotic Milling}

A sandstone sculpture of the Arms of Canada on the east facade of the West Block required repair due to the damage of various elements: the horn of the unicorn is missing, a lion that sits upon the centre crown is missing, and the crown that sits upon the lions head is damaged (Figure 7). Similar to the window reinstatement, plaster copies of the existing sculpture were not feasible. Each of the elements was digitized using both the close-range scanner as well as photogrammetry.

In this case, the nature of the repairs and the complexity of the forms required more than two-dimensional information to assist the masons. Two copies of each element were milled from rigid polyurethane foam using an industrial robot in place of the traditional plaster copies. The masons will then use the foam copies to plan the appropriate repair (Figure 8).

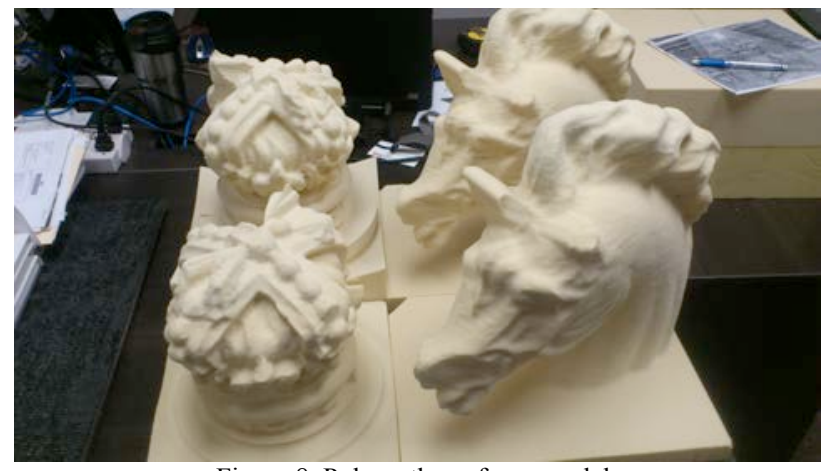

Figure 8. Polyurethane foam models

\subsection{Grotesque Head: Virtual Repair}

The head of a grotesque on the east facade of the West Block went missing at an unknown date in history. An intact companion grotesque of similar form exists, on the opposite corner from the headless one. Both grotesques were scanned with the close-range scanner (Figure 9).

Rather than robotically milling a copy of the existing grotesque to facilitate the repair, CIMS was tasked with using a digital workflow in parallel with the masons' traditional workflow. With the scan data as a base, and a grainy $100+$ year old photo as a guide, a new head was digitally sculpted using the threedimensional modelling software Sculptris by Pixologic (Figure 10). A physical copy of the replacement head was then 3Dprinted. This method was a proof-of-concept and ultimately not used in the repair. However, it points to the future where virtual repairs or replacement carvings might be done entirely digitally, including robotically milling the stone.

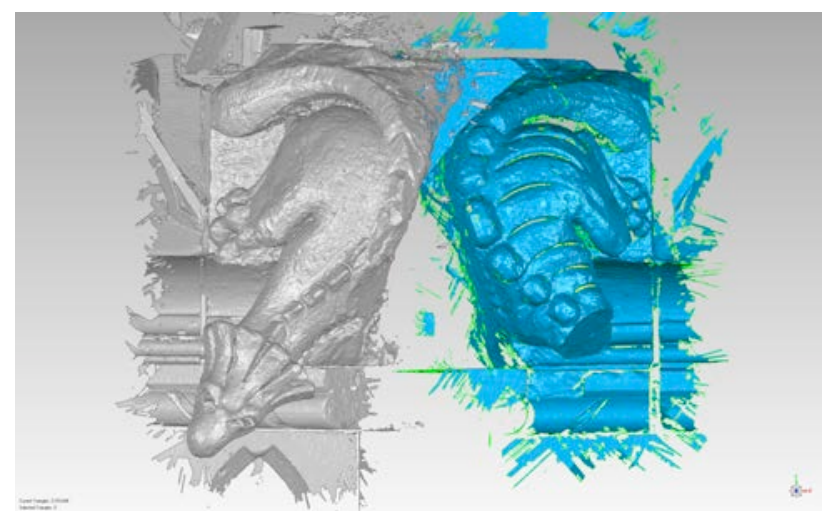

Figure 9. Adjacent Grotesques with and without head. 


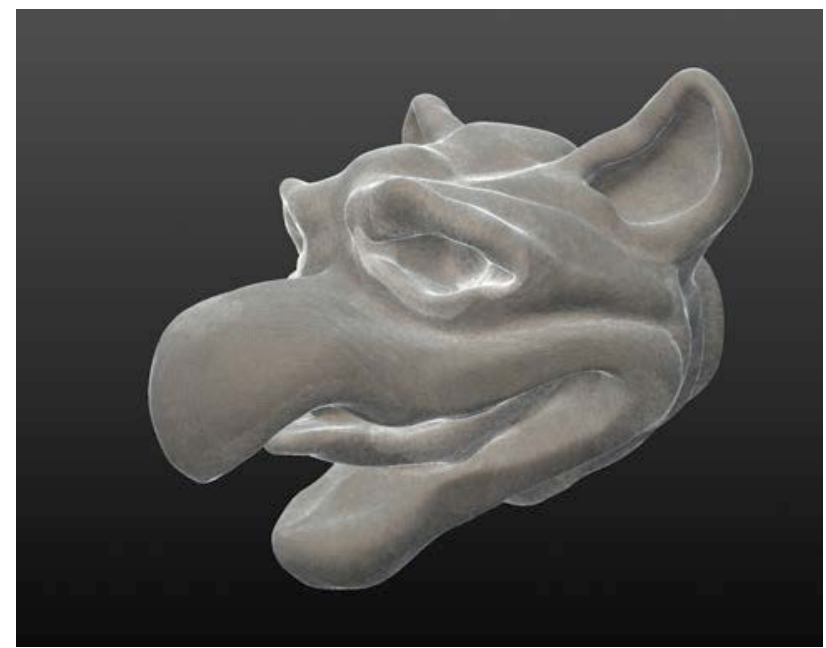

Figure 10. Head produced with modelling software

Stone carvers are a group whose working methods are steeped in tradition. The integration of data from close-range laser scanning and photogrammetry into the stone carvers methods was welcomed by the stone carvers to compare or supplement their traditional working.

\section{CONCLUSION}

Although it is too early to tell exactly what impact the documentation and dissemination of the heritage character defining sculptural elements of the Parliament Buildings will have on the general public and academia, certain results and benefits are already apparent for the client (PPB), stone carvers and the greater conservation team. In many instances the gathered data has guided or been used in order to form important conservation decisions. Through the collaboration of PPB, HCD, and CIMS, the rehabilitation projects have provided a mechanism to research and evolve practices helping to create a shared understanding of the tools, methods and techniques available to all parties involved in the conservation process. The resulting methodology and outcome cost a small percentage of the total rehabilitation budget. They have proved to be a fundamental reference tool combining new highly accurate usable information with data previously scattered throughout numerous individual reports. Ultimately, the result is the safeguarding of the historic fabric of Parliament Hill for the benefit of all Canadians and the greater conservation community.

\section{REFERENCES}

The Canadian Register of Historic Places, Parliament Hill (http://www.historicplaces.ca/en/rep-reg/place-

lieu.aspx?id=4681\&pid=0)

The CIPA $3 \mathrm{X} 3$ rules

(http://cipa.icomos.org/index.php?id=20\&tx_ttnews[tt_news] $=3$ $8 \& \mathrm{cHash}=5 \mathrm{~cd} 6 \mathrm{f} 8216 \mathrm{e} 31 \mathrm{~d} 77658 \mathrm{fc} 70 \mathrm{ca} 84 \mathrm{c} 7455 \mathrm{~d}$ ) 